\title{
De la filiación política al apoliticismo: las consecuencias de la anti-política en el derecho de participación
}

\author{
From political affiliation to apoliticism: the \\ consequences of anti-politics in the right of participation
}

\author{
Oswaldo Fidel Ycaza Vinueza
}

Recepción: 04 de septiembre de 2018

Aceptación: 10 de octubre de 2018

Resumen

Tradicionalmente, las bases del Estado ecuatoriano se han asentado sobre un modelo constitucional de corte garantista que protege, entre otros derechos, el de participación, particularmente el derecho de filiación política, enmarcado en un sistema de partidos, consolidado desde la década de los 70. Sin embargo, la creciente disconformidad ciudadana con el accionar de los partidos políticos tradicionales dio paso a un fenómeno denominado anti-política, basado en la deslegitimación de los partidos políticos y el surgimiento de movimientos sociales, como "verdaderas" instituciones de participación ciudadana, que requieren del poder político para la ejecución de sus postulados. Como consecuencia, el apoliticismo se ha impuesto como requisito para postular a cargos públicos en detrimento del derecho a la filiación política. A continuación se presenta un análisis de los efectos de la anti-política en el derecho a la participación política y el sistema de partidos.

Palabras clave: Anti-política, apoliticismo, filiación, movimientos políticos, participación, partidos políticos, sistema de partidos.

Abstract

Traditionally, the foundations of the Ecuadorean State have been bases on a protective constitutional model that guarantees, among others, the right to participation, particularly the right to political affiliation, framed on a consolidated parties system, since the 70s. However, the increasing citizen dissatisfaction with the actions of the traditional political parties gave way to the appearance of a new phenomenon called anti-politics, based on the delegitimation pf political parties and the emergence of social movements as the "true" institutions of citizen participation, which require political power to promote and execute its postulates. As a result, apoliticism has been imposed as a requirement to apply for public office positions, to the detriment of the right to political affiliation. An analysis is presented of the effects of antipolitics on the right to political participation and the parties system as a whole.
\end{abstract}

Key words: Anti-politics, apoliticism, affiliation, political movements, participation, political parties, party systems. 


\section{Introducción}

1 modelo constitucional ecuatoriano se allana a una tradición garantista de protección de los derechos de participación, particularmente, el derecho de filiación política. Dicha tradición de garantizar la filiación política no es nueva, sino que es el resultado de un proceso de construcción social y que ha superado doctrinas inspiradas en las que se hablaba de la “desestructuración del enemigo interno [...] por parte del núcleo más duro del poder económico que ha satelizado diferentes iniciativas de pensamiento crítico y renovador" (M.R.B., 2002: 12).

Pese a las limitaciones que debió enfrentar el pleno ejercicio del derecho de participación, encontramos que la Constitución Política del año 1979, enmarcada en el paradigma de la tercera ola de Democratización, garantizaba la igualdad ante la ley y la prohibición de toda discriminación por motivos de "[...] filiación, opiniones políticas o de cualquier otra índole."

La Constitución Política de la República del Ecuador aprobada el 5 de junio de 1998, entendió que el pleno ejercicio de los derechos civiles sólo era posible cuando "todas las personas sean consideradas iguales y gozarán de los mismos derechos, libertades y oportunidades, sin discriminación en razón de $[\ldots$ su $]$ filiación política".

Esta línea argumental tiene continuidad en la Constitución de la República del Ecuador del 2008, con énfasis en el reconocimiento del poder estatal de garantizar "el derecho a guardar reserva sobre sus convicciones. Nadie podrá ser obligado a declarar sobre las mismas. En ningún caso se podrá exigir o utilizar sin autorización del titular o de sus legítimos representantes, la información personal o de terceros sobre sus creencias religiosas, filiación o pensamiento político".

Todo este desarrollo normativo constituye un gran avance en materia de derechos, pero tiene un problema que tiene que ver con acontecimientos fácticos, ocurridos desde la vuelta a la democracia y los intentos de dinamitar el pensamiento crítico, en los que, no se utiliza la doctrina que habla de un enemigo interno sino que intenta incluso afectar la propia institucionalidad. 
En el presente trabajo revisaremos cómo el surgimiento del pensamiento que realza lo anti-político termina no sólo vulnerando el derecho de participación sino que se convierte en un deber que los ciudadanos certifiquen su condición apolítica para quienes aspiran a participar en los distintos concursos para desempeñar distintas funciones públicas.

A fin de evidenciar el efecto de la anti-política sobre el derecho de filiación política y garantía de reserva de éste, se analizará la incursión de la anti-política en el contexto nacional, la influencia en el actual sistema de partidos y los efectos en el ejercicio de los derechos de participación política y administrativos.

\section{Incursión de la anti-política en el contexto nacional}

La anti-política se formula desde lo discursivo, como una manifestación de la inconformidad que tiene la sociedad sobre sus representantes; así como el distanciamiento que existe entre los mandantes y quienes ocupan cargos de representación. La crítica formulada desde la ciudadanía es agravada por los desaciertos de la clase política que impulsaron prácticas excluyentes, tanto de la ciudadanía como de la propia militancia, prácticas clientelares y en beneficio propio, además de la incapacidad de adaptarse con rapidez a las nuevas demandas ciudadanas.

La ausencia de canales que permitan interactuar a mandantes y mandatarios ocasionó que la ciudadanía se considere ajena y muchas veces crítica, a la forma de cómo funcionan las instituciones del sistema operante. Como consecuencia, "la antipolítica irrumpe con fuerza en los años 80 y 90 del siglo pasado, aparece como critica a la ineficacia y corrupción de la política tradicional: la lógica tortuosa y de bloqueo decisional de los partidos y la ineficacia y corrupción de la burocracia pública, fenómenos a los cuales opone, las virtudes de la gestión tecnocrática, de las lógicas empresariales privadas, la espontaneidad y moralidad de la "sociedad civil", el valor de los independientes o outsiders, formas que aparecen como legítimas en cuanto se demuestren autónomas o independientes de los vínculos puestos por los políticos y por las instituciones de la representación, partidos y parlamento" 
(Cfr. Mastropaolo 2000 y Echeverría 2004 citado por Echeverría, 2006: 28)”.

La anti-política centra sus esfuerzos en desmantelar la institucionalidad, encontrando cabida en políticos de corte populista que intentan hacerse del apoyo de sectores de la población críticos de los poderes públicos, a quienes los identifica como contradictores y, por qué no decirlo, rivales. Quienes impulsan la tesis anti-política hacen suya la idea de que entre los partidos existen opuestos irreconciliables por el pensamiento político.

Contrario a doctrinas que defienden la institucionalidad de agresiones de quienes piensan distinto, la anti-política promueve replantearse la institucionalidad y encontrará, en actores populistas sus principales defensores, incapaces de entender que "aunque un partido solo representa a una parte, esta parte debe adoptar un enfoque no parcial del todo" (Sartori, 1999: 54); en este esquema, los acuerdos legislativos dejan de ser vistos como herramientas democráticas para la subsistencia de la institucionalidad y se convierten en pactos siniestros.

A diferencia del parlamentarismo donde "cualquier experimento populista encuentra grandes obstáculos en un contexto institucional en el que el Parlamento funciona y en el que los liderazgos derivan su legitimidad del apoyo parlamentario de partidos sólidos" (Pasquino, 2015: 29), el modelo presidencialista ecuatoriano coadyuvó al surgimiento de la anti-política, debido a que los candidatos buscan un discurso que se conecte con la inconformidad del elector.

En este contexto, la construcción de la partidocracia, entendida como el gobierno de los partidos mediante la exclusión de los ciudadanos, permitió concretar, para el caso ecuatoriano, el discurso anti-político y la consecuente necesidad de establecer alternativas a los partidos políticos. Siendo así, la instrumentación de la Constitución de la República del Ecuador permitió materializar esas creencias, ofreciendo un escenario de convivencia y cabida de la participación política y ciudadana.

La participación de la ciudadanía por su naturaleza puede desvincularse de la actividad partidaria; debido a que "el poder representativo funciona fundamentalmente en una lógica de suma cero, de suma negativa. Lo que 
en un proceso electoral gana uno, lo pierden los demás. Todas las decisiones distributivas están marcadas por esta lógica fatal. Por el contrario, el poder constitutivo no responde necesariamente a una lógica política basado en sumatorias negativas. La acción ciudadana tiene un inmenso potencial para generar escenarios de relacionamiento político desde los que se genere poder colectivo". (Montúfar, 2004: 101)

La participación ciudadana se constituye como la instancia en la cual, lejos de la política, aquellos que no confían o no comparten los mecanismos que establecen las instancias partidistas, puedan ser escuchados. La Constitución de la República del Ecuador contempla que las órbitas de la participación política y participación ciudadana tengan su propia institucionalidad que garantice su eficacia y desarrollo; así, la Función Electoral debe buscar que los distintos tipos de democracia (representativa, directa y comunitaria) sean ejercidos de forma efectiva por la ciudadanía; mientras que la Función de Transparencia y Control Social se encarga de velar porque los ciudadanos se empoderen de los mecanismos de participación.

\section{Influencia en el actual sistema de partidos}

El regreso de la democracia en la década de los 70 tuvo como actores principales a los binomios presidenciales promocionados por los partidos Liberal Radical Ecuatoriano; Concentración de Fuerzas Populares; Izquierda Democrática; Frente Radical Alfarista; Unión Democrática Popular; y la alianza política denominada "Frente Nacional Constitucionalista". Esta pluralidad de organizaciones políticas hizo que el naciente sistema de partidos sea concebido como una estructura cimentada en distintos planteamientos ideológicos, que posibilite que el relacionamiento político partidista parta de las coincidencias programáticas presentes entre los distintos actores.

A pesar de lo prometedor de volver a un sistema democrático, la percepción generada en la ciudadanía no era la mejor, debido a la postura de confrontación asumida por algunos líderes políticos, quienes se encargaron de que los acuerdos alcanzados sean denostados como maquinaciones de los grupos de poder, burlando el mandato popular. 
El intransitable sendero para alcanzar consensos comenzó a minar la confianza hacia los partidos políticos donde el discurso de la "antipolítica se constituyó en el pasaporte para que grupos emergentes de la sociedad civil, con la intención de convertirse en actores electorales, accedan a puestos nacionales y locales de representación" (Montúfar, 2004: 85). En este escenario, la movilización social se perfila como una alternativa de respuesta frente, a lo que consideran, un apático modelo de la democracia representativa.

La irrupción de la movilización social y gremial; y, particularmente, del movimiento indígena, a partir de la década de los 90, promovió el debate público sobre la necesidad de permitir la participación política de actores, esencialmente, sociales. De esta forma, “en 1994 la ciudadanía aprobó plebiscitariamente, la posibilidad de reformar la Constitución para que pudieran existir candidatos independientes a puestos de elección popular sin que necesariamente pertenezcan a algún partido. Esta reforma contradecía la ley original de 1979, cuyo objetivo era de institucionalizar al sistema de partidos, reconociendo únicamente a los candidatos respaldados por una agrupación legal. A partir de las elecciones generales en mayo de 1996, los candidatos quedaron habilitados para participar de manera independiente e individual, sin necesidad del auspicio de una organización política formal" (Mejía, 2002: 288).

Contrario a la formación de los partidos indirectos constituidos por sectores de la sociedad civil que en proceso de constitución "al lado de las afiliaciones colectivas de los sindicatos, cooperativas y otras agrupaciones socialistas, [... los partidos indirectos admiten] las afiliaciones individuales de hombres y mujeres que no son miembros de las anteriores organizaciones" (Duverger, 2012: 36); en el caso del sistema de partidos políticos se inclina por promover la partición política de movimientos sociales.

La Constitución Política del Ecuador aprobada el 5 de junio de 1998, reconoció en el ordenamiento constitucional la posibilidad de que los ciudadanos puedan fundar movimientos políticos ligando su existencia a obtener el cinco por ciento de los votos válidos en dos elecciones pluripersonales nacionales sucesivas, so pena de quedar cancelada su 
inscripción en el registro electoral en caso de no cumplir con el requisito. En sus primeras intervenciones, los movimientos políticos se concentrarán en responder a las exigencias coyunturales de sectores sociales que, a su decir, los partidos políticos no supieron atender en su momento.

El dilema del sistema de partidos derivado del surgimiento de los movimientos políticos se centrará en la interrelación entre éstos y los partidos políticos tradicionales; por lo que, el auge de los movimientos, como mecanismos alternativos de participación política, provocó el arrinconamiento de los partidos políticos.

El distanciamiento de la política partidista pretende ser vista como un hecho positivo en el ejercicio del sufragio pasivo; en ese contexto, la Ley de Elecciones de 2000 dio paso a la inscripción de candidaturas para dignidades de elección popular, nacional, provincial, cantonal o parroquial rural, sin estar afiliado o patrocinado por un partido político. Los candidatos independientes para legitimar su participación debían estar respaldados con la entrega de firmas equivalente al uno por ciento de los electores empadronados.

El argumento de la partidocracia no coadyuvaba en la ya crítica situación de los partidos políticos, en muchos casos, incapaces de hacer frente a las detracciones provenientes desde varios sectores. La anti-política estará presente en los acontecimientos que desembocaron en la Asamblea Constituyente de Montecristi, lo que significó que en la discusión de la Constitución de la República del Ecuador de 2008 tome fuerza la inclusión de organizaciones políticas nacional, regional, provincial, cantonal, parroquial y por el exterior.

El actual sistema de partidos se centra en dar respuesta a una de las críticas más frecuentes de los especulativos de la anti-política, que es la ausencia de debate al interior de los partidos políticos, para lo cual, se refuerza la necesidad de procesos de democracia interna en los cuales los afiliados o adherentes de las organizaciones políticas puedan participar en la elección de su dirigencia y candidatos.

El problema que surge de terciar en un proceso democrático, incluidas primarias, es el establecimiento de facciones al interior de la organización 
política, lo que en muchos de los casos, lejos de contribuir al fortalecimiento de las estructuras militantes, hace que se comiencen a generar crisis internas, crisis que verán en la creación de organizaciones políticas locales la posibilidad de concretar sus aspiraciones. En ese sentido, muchas de las organizaciones locales, contrario a su idea original de dar respuesta a demandas propias de una provincia, cantón o parroquia, se transforman en organizaciones satélites de partidos y movimientos nacionales, constituyéndose una réplica de sus principios filosóficos, políticos e ideológicos.

A pesar de la segmentación partidista, las elecciones seccionales no tienen una inclinación por las organizaciones políticas locales registradas exclusivamente para participar en dichos procesos electorales. Los candidatos de las organizaciones políticas de ámbito de acción nacional fueron electos para ocupar la mayoría de las prefecturas, alcaldías, concejalías urbanas y rurales y miembros de las Juntas Parroquiales, en las Elecciones Seccionales 2014.

\section{Cuadro 1.}

Candidatos electos por organización política

\begin{tabular}{l|c|c|c|c|c|c}
$\begin{array}{c}\text { Tipo de or- } \\
\text { ganización } \\
\text { política }\end{array}$ & $\begin{array}{c}\text { Prefectura / } \\
\text { viceprefec- } \\
\text { tura }\end{array}$ & $\begin{array}{c}\text { Alcaldías } \\
\text { munici- } \\
\text { pales }\end{array}$ & $\begin{array}{c}\text { Conce- } \\
\text { jalías } \\
\text { urbanas }\end{array}$ & $\begin{array}{c}\text { Conceja- } \\
\text { lías rurales }\end{array}$ & $\begin{array}{c}\text { Juntas Pa- } \\
\text { rroquiales }\end{array}$ & Total \\
\hline Nacionales & 12 & 139 & 532 & 278 & 2557 & 3518 \\
\hline Locales & 1 & 16 & 59 & 37 & 381 & 494 \\
\hline Total & 13 & 155 & 591 & 315 & 2938 & 4012
\end{tabular}

Fuente: CNE.

Por el contrario, los movimientos políticos de ámbito de acción local no alcanzaron su porcentaje base de participación en las Elecciones Seccionales 2014. Del número total de prefectos/vice-prefectos, los movimientos de ámbito local alcanzan una prefectura de las 13 en disputa, es decir un 4.34\%, cifra inferior al porcentaje de candidatos presentados por la organización política en comparación al total de candidaturas $6.89 \%$. En las demás 
dignidades se mantiene esta tónica de menor porcentaje de electos en relación con el porcentaje de participación.

\section{Efectos en el ejercicio de los derechos de participación política y administrativos}

El derecho de participación es entendido como la capacidad que tiene la ciudadanía para participar en los asuntos públicos, este derecho puede ser ejercido en dos niveles: Uno propiamente político, referente a elegir en procesos de democracia representativa, directa y comunitaria y ser elegido; y otro, de carácter administrativo, referente a ocupar un cargo público en condiciones de igualdad.

Ambos niveles en los cuales se desarrolla el derecho de participación se han visto sacudidos por la diatriba del apoliticismo, siendo la respuesta institucional el tratar de delimitar la participación política a aspectos exclusivamente partidistas. Desde luego, dicha pretensión parte de la probable injerencia de la clase política en aspectos sobre los que la ciudadanía tiene la titularidad.

La exigencia de marcar distancia entre la participación política y la participación ciudadana constituye un reclamo fundamental en la tesis de la anti-política, que menoscaba cualquier actividad partidista relacionada con el ejercicio de derechos a cargo de la ciudadanía; sin embargo, este planteamiento no ha considerado que se enfrenta a un débil sistema de partidos que hace muchos esfuerzos para soportar constantes embates.

De esta manera, resulta comprensible que se piense que las organizaciones políticas que se sobrepasen de su órbita restan legitimidad a la ciudadanía, pero tiene algún efecto, cuando sucede lo opuesto, cuando se debilita a las organizaciones políticas a causa de la menor participación de sus afiliados y adherentes.

Si bien en la legislación electoral ecuatoriana no existe la disolución de los partidos políticos a consecuencia de haber disminuido el total de 
sus afiliados en un determinado porcentaje en comparación del número exigido para su inscripción, no es menos cierto que experimentar constantes desafiliaciones no habla bien de un sistema de partidos.

La valoración negativa de la política se ha traducido en exigir que se certifique el apoliticismo de quienes desean ejercer su derecho de participación ante entidades de la administración pública; con lo cual, la garantía establecida en el artículo 66 de la Constitución de la República del Ecuador sobre la reserva de la filiación política es trastocada.

En otras palabras, el derecho de los ciudadanos de reserva acerca de su filiación o pensamiento político deja de ser una garantía constitucional y se convierte en una obligación, para los postulantes a un cargo público, quienes deben declarar que no han ejercido su derecho de filiación política y, lo que resulta más grave, renunciar a su pensamiento político en caso de pertenecer a un partido o movimiento.

La garantía, entendida como "cualquier técnica normativa de tutela de un derecho subjetivo" (Ferrajoli, 2006: 29) se traduce en el caso ecuatoriano, en la expectativa jurídica que la reserva de la información relativa a la filiación política sea tutelada por los poderes públicos. La fuerza del Estado debería estar decididamente orientada a proteger que los ciudadanos puedan ejercer con libertad su derecho de pertenecer a una organización política.

No obstante, en este particular contexto, la anti-política ha logrado posesionar su discurso de desprestigio de las organizaciones políticas y de sus miembros. Quienes desempeñan funciones públicas revalidan esta idea, al ligar su idoneidad por su distanciamiento con las organizaciones políticas legalmente constituidas; sin considerar que su acervo ideológico les permitirá actuar con honestidad.

\section{Reflexiones finales}

La anti-política emerge en los años 80 y 90 como crítica a las prácticas desarrolladas por la clase política, particularmente, por su distanciamiento 
con los ciudadanos. La ciudadanía exige alternativas a la que consideran inacción de sus representantes y consideran indispensable establecer y empoderarse de los mecanismos que permitan a la ciudadanía participar en la toma de decisiones.

La acción ciudadana tendrá una respuesta institucional y legal, a través del reconocimiento de mecanismos de participación paralelos a la actividad política partidista. Los mecanismos creados para la participación ciudadana se centran en garantizar la participación en la construcción, ejecución y evaluación de las políticas públicas; no obstante, estos deben observar los procedimientos fijados por los entes públicos.

Seguramente, esta limitación ha significado que la anti-política encuentre espacios en el propio sistema de partidos; la crítica inicial de ausencia de canales de diálogo provocó que los sectores sociales organizados se decanten por la formación de movimientos políticos indirectos, cimentados en los postulados de una agremiación o sector social determinado, para que, en su momento y, a través de elecciones populares alcancen el poder y puedan ser ejecutados.

La idea de las organizaciones sociales de incursionar en la actividad partidista se concretó con el registro por parte de la autoridad electoral de movimientos políticos destinados a atender una coyuntura que justificaba su origen. El auge del discurso de la anti-política impulsó la idea de que los movimientos constituyen una alternativa para que la población, hasta entonces relegada, forme parte del gobierno y participe en sus decisiones.

El discurso sobre el gobierno de los partidos alejados de la ciudadanía tuvo como propósito descalificar con mayor vehemencia a las estructuras político - partidistas y a los políticos tradicionales; el argumento sobre lo lesivo de la partidocracia será preponderante para la diversificación de los movimientos políticos. De este modo, la Constitución de la República del Ecuador dio paso a que se piense que desde lo local se puedan organizar movimientos políticos.

El apartamiento de los partidos políticos con la militancia local, concentraba la gestión en líderes locales cercanos a la dirigencia central, 
dejando fuera del debate interno los asuntos propios de la localidad. Sin embargo, los movimientos de ámbito provincial, cantonal o parroquial, lejos de responder a las exigencias democráticas que avalaron su irrupción en el sistema de partidos, se han reducido en fomentar liderazgos locales, evidenciados por un número cada vez mayor de organizaciones políticas de acción local y una escasa representatividad concedida a las mismas.

Los efectos de las tesis que consideran a la política partidista como algo pernicioso, no se limita a una justa aspiración de diferenciar la participación política y la participación ciudadana sino que la anti-política tiene cabida incluso en la propia política y sus relaciones de poder. La exigencia de certificar su apoliticismo a quienes deciden postular para ocupar una instancia determinada del poder público no constituye una muestra de vinculación con la ciudadanía.

Considerar al apoliticismo como un factor que avale que las actuaciones de un funcionario público pensando en lo general y no en beneficio de un sector concreto, muchas veces encierra más dudas que certezas; sin embargo, la afectación que crean en el sistema de partidos es real. La consideración negativa sobre quienes han decidido ejercer su derecho a la filiación política constituye un debilitamiento deliberado de las organizaciones políticas, que ocasiona un estremecimiento de sus estructuras con cada convocatoria a un concurso de méritos y evaluación, debido a los efectos que puede tener una desbandada de sus afiliados o adherentes, quienes forzosamente se encuentran en la encrucijada de tener que decidir si postularse o mantener su afiliación política.

Las prácticas e injerencias de ciertos líderes políticos, que han buscado deslegitimar a la actividad política, tiene como efecto la vulneración al derecho de filiación política cuya reserva se encuentra tutelada por la Constitución de la República del Ecuador, pero que ahora pasó a convertirse en un deber de publicidad del ciudadano en favor del Estado.

La anti-política ha logrado materializarse a través de la instrumentación de varias acciones tendientes a limitar la influencia de la clase política, las estructuras partidistas y los propios actores políticos, frente a excesos que 
afecten a la ciudadanía y su participación. El reconocimiento de la existencia de lógicas diferentes entre la participación política y la participación ciudadana permitiría que cada una tenga su ámbito plenamente identificado, sin que exista ningún tipo de intromisión mutua.

El reconocimiento realizado por los partidos políticos en su momento no sólo fue en favor de la participación ciudadana, sino en reconocer otros mecanismos de organización política, como son los movimientos políticos. Los movimientos políticos aparecen para dar respuesta a las demandas coyunturales, tanto sectoriales como locales, que no fueron atendidos por la pluralidad de las ideologías partidistas; no obstante, la expectativa tendrá que hacer frente a la realidad que ve que la inconformidad se acrecienta sin que ningún mecanismo cumpla con su propósito de democratizar la participación. En este sentido, se hace necesario un replanteamiento del actual sistema de partidos que re-legitimice la existencia de los partidos políticos como elemento esencial de los regímenes democráticos y que, a su vez, otorgue los espacios propicios e idóneos para el desarrollo de los movimientos sociales, con el fin de que alcancen la satisfacción de sus demandas específicas sin tener que recurrir al juego político de suma-cero, bajo el convencimiento inducido de que la única forma de promover su lucha es el poder popular.

Finalmente, es fundamental que la ciudadanía se despoje de la vieja imagen de los partidos políticos y construya un nuevo escenario que dé cabida al consenso y al disenso entre postulados ideológicos diversos. Esto permitirá que los individuos puedan gozar efectivamente del derecho a la libertad de pensamiento en todas las esferas de la sociedad.

\section{Referencias}

Echeverría, J. (2007). "La Democracia Difícil: Neopopulismo y Anti - política en Ecuador”, ICONOS: Revista de Ciencias Sociales N 27, pp. 27.35, FLACSO.

Ferrajoli, L. (2006). Sobre los Derechos Fundamentales y sus Garantías. 
México: CNDH.

Duverger, M. (2012). Los Partidos Políticos. México: Fondo de Cultura Económica.

M.R.B., (2002). La Democracia Bajo Reglas de Excepción. Mientras Tanto, 84, pp. 11-18, Icaria Editorial.

Montúfar, C. (2004). “Anti-política, Representación y Participación Ciudadana", Revista Ecuador Debate N 62, pp. 83-102.

Mejía, A. (2002). "Partidos Políticos: El Eslabón Perdido de la Representación", Gobernabilidad Democrática. Sistema electoral, Partidos Políticos y Pugna de Poderes en Ecuador. pp. 287-324, Fundación Konrad Adenauer.

Pasquino, G. (2015). "Populismo, Instituciones y Unión Europea”. Cuadernos de Pensamiento Político $\mathrm{N}^{\circ}$ 47, pp.21-34, FAES, Fundación para el Análisis y los Estudios Sociales.

Sartori, G. (1999) Partidos y Sistemas de Partidos. Madrid: Alianza Editorial. 